\title{
Impact of Dentofacial Deformity on Quality of Life: Age and Gender Differences Evaluated Through OQLQ, OHIP and SF36
}

\author{
Marcelo Carlos Bortoluzzi ${ }^{1}$, Priscila de Camargo Smolarek ${ }^{1}$, Marcela Claudino ${ }^{1}$, Eduardo B. \\ Campagnoli ${ }^{1}$, Rafael Manfro ${ }^{1}$
}

${ }^{1}$ School of Dentistry, Dentistry Department, Ponta Grossa State University, Ponta Grossa, Paraná, Brazil.

\author{
Corresponding Author: \\ Marcelo Carlos Bortoluzzi \\ Departamento de Odontologia, Faculdade de Odontologia \\ University \\ Av. General Carlos Cavalcanti, 4748 - CEP 84.030-900 \\ Bloco M, Ponta Grossa, Paraná \\ Brazil \\ Phone: + 554232203104 \\ E-mail: mbortoluzzi@gmail.com
}

\begin{abstract}
Objectives: The aim of this study was to verify the impact of dentofacial deformity on quality of life and explore gender and age differences.

Material and Methods: The impact of dentofacial deformity (DD) on quality of life was evaluated through questionnaires; Short Form Health Survey (SF36), Oral Health Impact Profile Questionnaire (OHIP), Orthognathic Quality of Life Questionnaire (OQLQ) and a single question answered by a Visual Analogue Scale.

Results: Significant differences between male and female patients were observed in domains of OQLQ (oral function, $\mathrm{P}=0.006$; awareness of facial deformity, $\mathrm{P}=0.018$; and facial aesthetics, $\mathrm{P}<0.001$ ) and OHIP (physical pain, $\mathrm{P}=0.006$; psychological discomfort, $\mathrm{P}=0.007$; psychological disability, $\mathrm{P}=0.006$; and handicap, $\mathrm{P}=0.01$ ).

Conclusions: The impact of dentofacial deformity was more pronounced in female Brazilian population. Age of patients with dentofacial deformity produced impacts over quality of life in different ways and according to the applied questionnaire and the interaction between age and gender may also produce different impacts in patients with dentofacial deformity. The domains of Orthognathic Quality of Life Questionnaire, Oral Health Impact Profile Questionnaire and Short Form Health Survey showed unaccepted distances in the pattern of answer rising doubts of their ability to assess quality of life as a generic and broad concept. There is a necessity to create a single quality of life instrument capable to measure impacts with sensitivity and specificity and from a generic concept to condition-specific health problem.
\end{abstract}

Keywords: dentofacial deformities; quality of life; oral health; questionnaires.

Accepted for publication: 19 August 2015

To cite this article:

Bortoluzzi MC, de Camargo Smolarek P, Claudino M, Campagnoli EB, Manfro R.

Impact of Dentofacial Deformity on Quality of Life: Age and Gender Differences Evaluated Through OQLQ, OHIP and SF36. J Oral Maxillofac Res 2015;6(3):e3.

URL: http://www.ejomr.org/JOMR/archives/2015/3/e3/v6n3e3.pdf

doi: $10.5037 /$ jomr.2015.6303 


\section{INTRODUCTION}

Efforts have been made to develop quality of life (QOL) questionnaires focused in the disease or condition-specific. Those questionnaires claim to be better for measure the impact of QOL for specific conditions when compared with general QOL questionnaires [1]. However, as more specific is the questionnaire more generalities of QOL may be lost and it contradicts the primary concept for QOL, as described by the World Health Organization (WHO) [2] which declare that QOL is; "an individual's perception of their position in life in the context of the culture and value systems in which they live and in relation to their goals, expectations, standards and concerns". Due to this reason, some authors have suggested the use of both QOL questionnaires the condition-specific QOL and the generic QOL questionnaires to provide an effective combination of measures [3-5]. Nevertheless, it is not clear how to analyze those data, or how to combine those measures to understand effectively how much the specific disease or condition in patients mouth really affect their overall QOL.

Accordingly to Proffit et al. [] dentofacial deformity (DD) may be defined as facial and dental disproportions great enough to significantly affect the individual's QOL. This population is being considered handicapped, functionally and/or socially, by dental and facial components that are far enough outside the range of normal to broadly affect adjustments to life. Still accordingly to those previous authors [6] these individuals must constantly take into account the effect of their mismatched jaws in everyday things such as what they can eat in public without embarrassment or whether they will be considered stupid, mean, or angry when they meet others just because of their facial appearance. It also has been declared that patients with DD are at a disadvantage in society due to low self-esteem and decreased levels of confidence, as well as associated physiological problems [7]. These important impacts in life aspects such as oral function, appearance and interpersonal relationships were also evidenced by others $[\underline{4}, \underline{8}, \underline{9}]$.

The aim of this study was to verify the impact of DD on quality of life through different questionnaires, a generic health related questionnaire (Short Form Health Survey - SF36), a generic oral health-related (Oral Health Impact Profile Questionnaire - OHIP), a condition-specific for dentofacial deformity (Orthognathic Quality of Life Questionnaire - OQLQ) and a single question answered by a Visual Analogue Scale (VAS). The study also aimed to explore gender and age differences through those instruments.

\section{MATERIAL AND METHODS}

This study was approved by a local Ethical Committee for Human Research, it is in accordance with Helsinki Declaration and all participants provided a signed informed consent. A convenience sample of 53 consecutive subjects with DD were interviewed while searching for dental treatment, orthodontic treatment or searching for specific treatment for DD. This research was based into two universities, Ponta Grossa State University (UEPG-Brazil) and West of Santa Catarina University (UNOESC-Brazil). The diagnosis for DD followed the standard literature concepts [] and were made exclusively by orthodontists or maxillofacial surgeons invited. All perssonal enrolled in this research received full instructions concerning the methods. Cephalometric analysis was performed only for patients who were enrolled into presurgical orthodontic treatment. Clinical diagnosis of mandibular prognathism, mandibular retrognathism, anterior open bite, laterognathism, vertical maxillary excess or a combination of these health problems were made and the patient were asked to participate and answer the questionnaires after a full explanation of the objectives of the research. Previous orthognathic surgery, syndromes or congenital deformities such as cleft lip and palate, trauma sequel and edentate patients were excluding criteria. Instructions about how to answer the questionnaires were given to the patients and any doubt over the questions could be solved by a researcher assistant. The impact of DD over QOL was evaluated through a generic QOL questionnaire (Short Form Health Survey - SF36), a generic oral healthrelated (Oral Health Impact Profile Questionnaire OHIP-49), a condition-specific for DD (Orthognathic Quality of Life Questionnaire - OQLQ) and a single question answered by a Visual Analogue Scale (VAS).

The OQLQ consists of 22 items on a 4-point scale rating and coded as follows: from 1 or "it bothers you a little" to 4 or "it bothers you a lot", being 2 and 3 in between; and NA or "the statement does not apply to you or does not bother you". The 22 items are divided into concerns or domains regarding as social aspects of deformity (first component), facial aesthetics (second component), oral function (third component) and awareness of facial deformity (fourth component). The scoring of the OQLQ is performed by addition of individual items within the domains. A total OQLQ score can range from 0 to 88 , with domains counting specifically (social aspects domain, 0 - 32; dento-facial aesthetics domain, 0 - 20; function domain, 0 - 20; and awareness of dento-facial aesthetics, 0 - 16). A higher score indicates poorer QOL and a lower score 
better QOL $[1,10,11]$.

The OHIP questionnaire is a 49 -question instrument developed by Slade and Spencer [12] and was conceived to measure how different oral conditions affect quality of life in an overall sense. It is organized in seven conceptual impact dimensions: "functional limitations", "physical pain", "psychological discomfort", "physical disability", "psychological disability", "social disability" and "handicap". The OHIP-49 domains range from 0 - 40 and the values are obtained through a weighted average of the questions which compose each dimension. Higher scores indicate a worse oral health-related quality of life state [13].

The Brazilian version of the generic SF36 consists of 36 statements divided into 8 domains: physical functioning, physical role, bodily pain, general health, vitality, social functioning, emotional role and mental health. For each subscale, raw data are transformed and summed on a $0-100$ scale with a higher score indicating better health state $[14,15]$.

Visual Analogue Scale (VAS) was ranging from 0 to 100 with higher scores indicating better QOL state. This single answer scale brings information and concepts of generic QOL and after read the patient ponders indicating a point in the scale that better describes his/her actual QOL.

\section{Statistical analysis}

Data were analyzed through statistical software STATA 8.0 at a level of significance of $\mathrm{P} \leq 0.05$ (confidence interval of 95\%). Data obtained from questionnaires were first evaluated descriptively through means and standard deviations (M [SD]). The questionnaires scores differences between gender were further statistically analyzed through Mann-Whitney Test. The relation between age (dependent variable) and domains of OQLQ, OHIP, SF36 and VAS (independent variables) were also analyzed through Stepwise Multiple Linear Regression with and without gender influence. A Cluster Analysis generated a dendrogram showing the proximity/distance for the answer pattern for domains of OQLQ, OHIP, SF36 and VAS.

\section{RESULTS}

The sample was composed by 53 patients with light predominance of female (30 patients $56.6 \%$ ). The age ranged between 15 and 52 years (mean 28.9 [9.7]). For male patients the mean age was $27.3(8.8)$ years while for female was $30.2(10.3)$ years with no significant differences (Independent $\mathrm{T}$ test $\mathrm{P}=0.2$ ). The QOL scores measured through OQLQ, OHIP, SF36 and VAS was summarized in Table 1 . Table 2 shows the statistical analyzes and differences between the scores for QOL in the all domains questionnaires and VAS in patients with DD distributed by gender. Significant differences between male and female patients were observed in domains of OQLQ (oral function, awareness of facial deformity and facial aesthetics) and OHIP (physical pain, psychological discomfort, psychological disability and handicap) showing that the impact of DD over QOL was more pronounced in female patients.

To observe how the domains of OQLQ, OHIP, SF36 and VAS are related, they were analyzed through Hierarchical Cluster Analysis (Nearest Neighbor, Squared Euclidean distance - standardized by Z scores and rescaled from 0 to 1 ) which generated a dendrogram (Figure 1). For this analysis the scores of OHIP and OQLQ were inverted to keep the scores for QOL in a single direction (higher score indicates better quality of life) through the formula (Inverted score domain $=$ maximum score domain value - original score domain value).

A complementary analysis showed that age was weakly and positively correlated with OQLQ domains of "facial aesthetics" (Spearman Test $\mathrm{r}=0.3 ; \mathrm{P}=0.027$ ) and "oral function" (Spearman Test $\mathrm{r}=0.3 ; \mathrm{P}=0.019$ ). For all OHIP domains and VAS none correlation was observed with age. For SF36 age showed negative correlation with domains "role limitations due to physical health" (Spearman Test $\mathrm{r}=-0.3 ; \mathrm{P}=0.005$ ) and "pain" (Spearman Test $r=-0.2 ; P=0.04)$. A Stepwise Multiple Linear Regression Analysis was performed considering age as dependent variable and all questionnaires domains and VAS as independent (Table 3).

\section{DISCUSSION}

Health-related quality of life is a multidimensional concept representing a combination of absolute health, perceptions of actual or potential health, and/or disability [16]. DD is a complex problem which truly affects different aspects of an individual [5-7, $, 9, \underline{15}$ ]. As well as DD, the complexity is also extended to the dynamics of QOL phenomenon and its betweensubjects differences, conditions and/or diseases [17]. This study aimed to explore the impact of DD on QOL through a range of questionnaires and questions from generic, passing through generic oral health measures and to DD condition-specific QOL, seeking to analyze and understand the relations between those questionnaires domains observing the inequalities among gender and age. 
Table 1. Quality of life in 53 patients with dentofacial deformity evaluated through Orthognathic Quality of Life Questionnaire (OQLQ), Oral Health Impact Profile (OHIP-49), Generic form of the SF36 and a Visual Analoge Scale

\begin{tabular}{|c|c|c|c|}
\hline Questionnaires and conceptual domains & Possible variations & Mean & Standard deviation \\
\hline \multicolumn{4}{|l|}{ OQLQ $^{\mathrm{a}}$} \\
\hline Social aspects of deformity & $0-32$ & 10 & 9.4 \\
\hline Facial aesthetics & $0-20$ & 10 & 5.8 \\
\hline Oral function & $0-20$ & 8.1 & 6.2 \\
\hline Awareness of facial deformity & $0-16$ & 7.1 & 4.9 \\
\hline OQLQ total range & $0-88$ & 35.3 & 22.3 \\
\hline \multicolumn{4}{|l|}{ OHIP-49 } \\
\hline Functional limitation & & 13.8 & 8 \\
\hline Physical pain & & 11.8 & 8.9 \\
\hline Psychological discomfort & $0-40$ & 20.1 & 13.2 \\
\hline Physical disability & & 10.3 & 10 \\
\hline Psychological disability & & 10.9 & 11.3 \\
\hline Social disability & & 6.1 & 10.1 \\
\hline Handicap & & 6 & 9.2 \\
\hline OHIP-49 total range (mean of the domains) & $0-40$ & 11.3 & 9 \\
\hline \multicolumn{4}{|l|}{ SF36 $^{\text {b }}$} \\
\hline Physical functioning & & 87.7 & 15.5 \\
\hline Role limitations due to physical health & & 71.2 & 36.4 \\
\hline Role limitations due to emotional problems & & 70.4 & 40.1 \\
\hline Energy/ fatigue & & 63.9 & 18.6 \\
\hline Emotional well being & $0-100$ & 66.6 & 21.4 \\
\hline Social functioning & & 76.8 & 21.2 \\
\hline Pain & & 70 & 22.4 \\
\hline General health & & 64.3 & 17.9 \\
\hline Visual Analogue Scale $^{\text {b }}$ & $0-100$ & 76.7 & 17.2 \\
\hline
\end{tabular}

${ }^{a}$ Higher score indicates poorer quality of life.

${ }^{b}$ Higher score indicates better quality of life.

Table 2. Quality of life scores distributed by gender and evaluated through Orthognathic Quality of Life Questionnaire (OQLQ), Oral Health Impact Profile (OHIP-49), Generic form of the SF36 and a Visual Analoge Scale

\begin{tabular}{|c|c|c|c|}
\hline Questionnaires and conceptual domains & Gender & Mean & Mann-Whitney (CI 95\%) \\
\hline \multicolumn{4}{|l|}{ OQLQ $^{\mathrm{a}}$} \\
\hline Social aspects of deformity & $\begin{array}{l}\text { Male } \\
\text { Female }\end{array}$ & & NS \\
\hline Facial aesthetics & Male & & \multirow{2}{*}{$\mathrm{P}<0.001$} \\
\hline 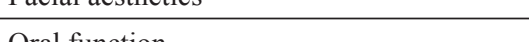 & $\frac{\text { Female }}{\text { Male }}$ & 6 & \\
\hline Oral function & Female & & $\mathrm{P}=0.006$ \\
\hline Awareness of facial deformity & $\begin{array}{l}\text { Male } \\
\text { Female }\end{array}$ & & $\mathrm{P}=0.018$ \\
\hline OQLQ Total range & $\begin{array}{l}\text { Male } \\
\text { Female }\end{array}$ & $\frac{25}{432}$ & $\mathrm{P}=0.003$ \\
\hline \multicolumn{4}{|l|}{ OHIP-49 ${ }^{\mathrm{a}}$} \\
\hline Functional limitation & $\begin{array}{l}\text { Male } \\
\text { Female }\end{array}$ & $\frac{4}{5}$ & NS \\
\hline Physical pain & $\frac{\text { Male }}{\text { Female }}$ & & $\mathrm{P}=0.006$ \\
\hline Psychological discomfort & $\begin{array}{l}\text { Male } \\
\text { Female }\end{array}$ & & $\mathrm{P}=0.007$ \\
\hline Physical disability & $\begin{array}{l}\text { Male } \\
\text { Female }\end{array}$ & & $\mathrm{NS}$ \\
\hline Psychological disability & $\begin{array}{l}\text { Male } \\
\text { Female }\end{array}$ & & $\mathrm{P}=0.006$ \\
\hline Social disability & $\begin{array}{l}\text { Male } \\
\text { Female }\end{array}$ & & NS \\
\hline Handicap & $\begin{array}{l}\text { Male } \\
\text { Female }\end{array}$ & $\frac{4.2}{7.4}$ & $\mathrm{P}=0.01$ \\
\hline OHIP-49 Total range & $\begin{array}{l}\text { Male } \\
\text { Female }\end{array}$ & & $\mathrm{P}=0.004$ \\
\hline \multicolumn{4}{|l|}{ SF36 $^{\mathrm{b}}$} \\
\hline Physical functioning & $\frac{\text { Male }}{\text { Female }}$ & $\frac{85.6}{89.3}$ & NS \\
\hline Role limitations due to physical health & $\begin{array}{l}\text { Male } \\
\text { Female }\end{array}$ & $\frac{75}{68.3}$ & NS \\
\hline Role limitations due to emotional problems & $\begin{array}{l}\text { Male } \\
\text { Female }\end{array}$ & $\begin{array}{l}73.9 \\
67.7\end{array}$ & NS \\
\hline Energy/fatigue & $\begin{array}{l}\text { Male } \\
\text { Female }\end{array}$ & $\frac{65.4}{62.8}$ & NS \\
\hline Emotional well being & $\begin{array}{l}\text { Male } \\
\text { Female }\end{array}$ & $\frac{69.3}{64.5}$ & NS \\
\hline Social functioning & $\begin{array}{l}\text { Male } \\
\text { Female }\end{array}$ & $\begin{array}{l}80.4 \\
74.1\end{array}$ & NS \\
\hline Pain & $\begin{array}{l}\text { Male } \\
\text { Female }\end{array}$ & $\begin{array}{l}70.9 \\
69.2\end{array}$ & NS \\
\hline General health & $\begin{array}{l}\text { Male } \\
\text { Female }\end{array}$ & $\frac{61.7}{66.3}$ & NS \\
\hline Visual Analogue Scale ${ }^{b}$ & $\begin{array}{l}\text { Male } \\
\text { Female } \\
\end{array}$ & $\frac{80.9}{73.4}$ & NS \\
\hline
\end{tabular}

aHigher score indicates poorer quality of life.

${ }^{b}$ Higher score indicates better quality of life.

NS $=$ Non significant differences. 
Table 3. Relationship between age (dependent variable) and domains of Orthognathic Quality of Life Questionnaire (OQLQ), Oral Health Impact Profile (OHIP-49), Generic form of the SF36 and a Visual Analoge Scale (independent variables) through Stepwise Multiple Linear Regression analysis without gender influence and controlled by gender

\begin{tabular}{|c|c|c|c|c|c|}
\hline \multicolumn{2}{|c|}{$\begin{array}{l}\text { Stepwise Multiple Linear Regression } \\
\text { (not controlled by gender) }\end{array}$} & \multicolumn{2}{|c|}{ Significance } & \multicolumn{2}{|c|}{ 95\% Confidence Interval for B } \\
\hline $\mathbf{R}$ & R Square & B & $\mathbf{P}$ & Lower Bound & Upper Bound \\
\hline 0.49 & 0.24 & & & & \\
\hline \multicolumn{2}{|c|}{ OQLQ Oral Function } & 0.84 & 0.000 & 0.4 & 1.2 \\
\hline \multicolumn{2}{|c|}{ SF36 Emotional well being } & 0.17 & 0.008 & 0.047 & 0.29 \\
\hline \multicolumn{6}{|c|}{ Stepwise Linear Regression (female) } \\
\hline 0.59 & 0.35 & & & & \\
\hline \multicolumn{2}{|c|}{ SF36 Emotional well being } & 0.29 & 0.001 & 0.12 & 0.46 \\
\hline \multicolumn{2}{|c|}{ OQLQ Facial aesthetics } & 1 & 0.008 & 0.28 & 1.7 \\
\hline \multicolumn{6}{|c|}{ Stepwise Linear Regression (male) } \\
\hline 0.81 & 0.66 & & & & \\
\hline \multicolumn{2}{|c|}{ Visual Analogue Scale } & -0.34 & 0.003 & -0.55 & -0.13 \\
\hline \multicolumn{2}{|c|}{ SF36 Role limitations due to physical health } & -0.15 & 0.001 & -0.23 & -0.06 \\
\hline \multicolumn{2}{|c|}{ OHIP Social disability } & -0.45 & 0.017 & -0.81 & -0.08 \\
\hline
\end{tabular}

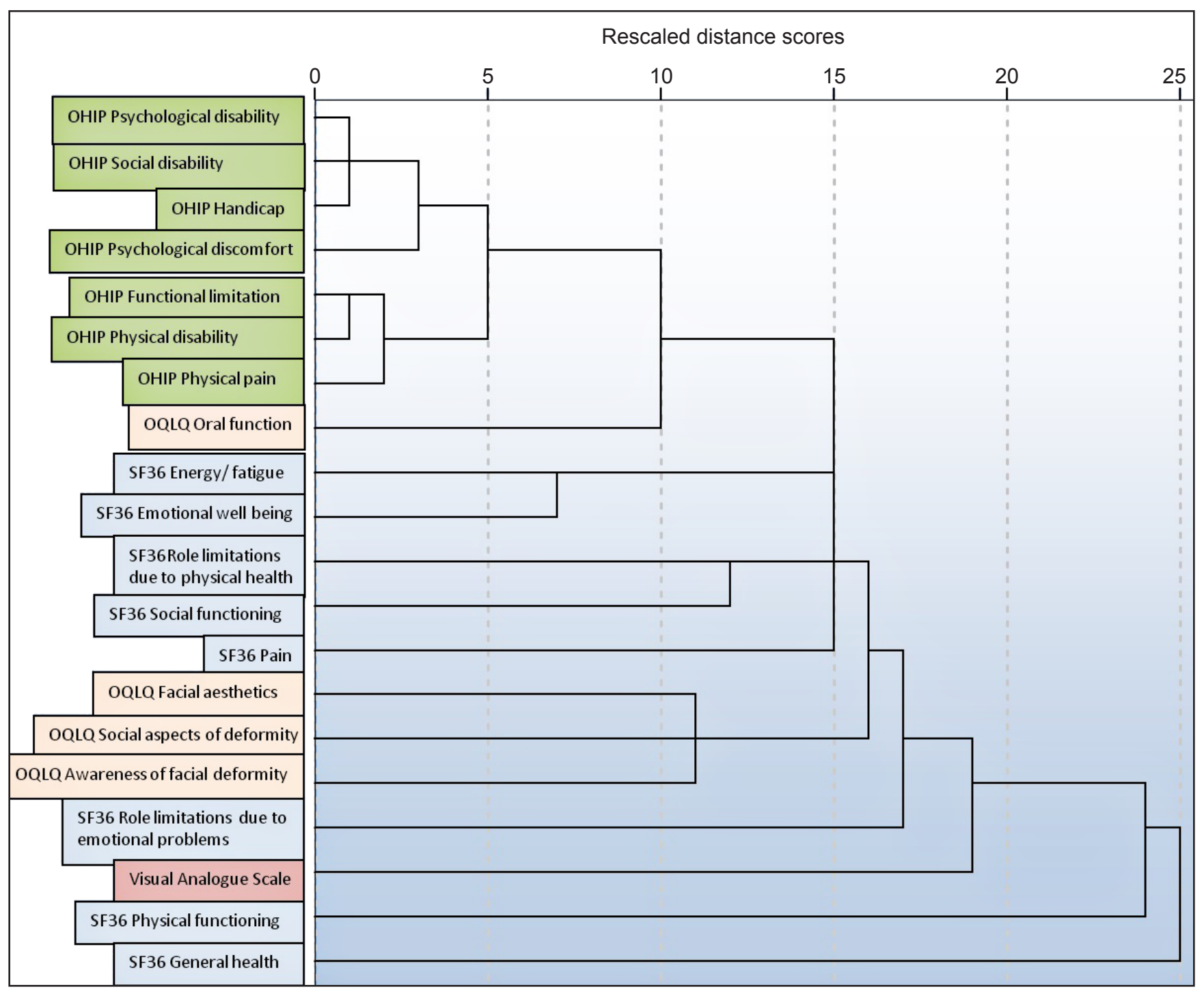

Figure 1. Dendrogram of rescaled distance cluster analysis for domains of Orthognathic Quality of Life Questionnaire (OQLQ), Oral Health Impact Profile (OHIP-49), Generic form of the SF36 and a Visual Analoge Scale. 
Few studies compared the impact of DD over the QOL between male and female patients. Bock et al. [] using an OQLQ slight different and adapted to German language (OQLQ-24 questions) observed that, for that population, male patients claim that they were more depressed because of their appearance or that they were more hurt by remarks about their appearance, and those results were very different than the observed in these Brazilian sample where female showed negative QOL impacts when compared to male in all OQLQ domains but statistically high enough impact in three domains (facial aesthetics, oral function and awareness of facial deformity). Our results are also not in accordance with the results described by Choi et al. []ㅡ who observed no significant differences between male and female patients from Singapore with DD evaluated through SF36, OHIP-14 and OQLQ questionnaires. This present study observed an outstanding differences in the pattern of answer between gender (Table 1) and it was observed that OQLQ and OHIP were statistically different in most domains when gender are compared, with important and negative impact over QOL predominantly observed in female patients, however, no differences was observed in the pattern of gender answer for SF36 and VAS. Considering the Brazilian population, Esperão et al. [18] using OHIP14 to measure the impact of DD over QOL observed that women patients report a greater impact than male patients of their oral status on QOL, whether or not they had started orthodontic treatment or completed orthognathic surgery and those results were similar to what was observed in our study, considering the analysis methods and differences between both studies.

Our results showed that the age of the patients with DD produced impacts over QOL in different ways. Using OQLQ, the correlation analysis showed that as older is the patient greater is the negative impact over QOL mainly in facial aesthetics and oral function domains, while OHIP didn't show any fluctuations in QOL according age. Using SF36, the correlation analysis showed that the increase of age produces more limitations due to physical health and more claims of pain. A second analysis explored all questionnaires domains in a stepwise multiple linear regression controlled and not controlled by gender, which also showed different statistical relationship and impacts over QOL (Table 3) and those are, essentially, not similar according gender. For female patients with DD our results showed that age increase the negative impact on facial aesthetics but improve the emotional well being, while for male patients as age progress greater is the limitations due to physical health, however, greater is the generic QOL as a whole (VAS) and, the social disability due oral health problems (OHIP) get improved. This present study becomes unique since it used four different techniques to evaluate the impact of DD over QOL, but more specifically, it showed how different is those impacts in QOL are concerning age and gender. In the literature review applied to this research this is the first time that these differences between age and gender in QOL of patients with DD are reported.

Impairment and illness described by questionnaires domains may reflect function at the social, psychological or physical levels, as well as perceptions of health. One of the objectives of this study was also to explore the relationship between questionnaires domains through hierarchical cluster analysis and observe the proximity (Figure 1) of answer pattern according to the "meaning", and the observed showed that those questionnaires domains may not have the same meaning or proximity as expected. For instance, we expected a close proximity of the social domains like social aspects of deformity (OQLQ), social disability (OHIP) and social functioning (SF36) but that was not the case. Allison et al. [17] explain that the differences between questionnaires domains and measures may rely in the nature of the question, the context that those are applied, and the dynamics of QOL between-subjects. Therefore, understanding the impact of a condition on QOL through the combination of generic-specific instruments may not be a reasonable option because, mathematically, it appears that those questionnaires are not measuring the same thing, at least in domain analysis. These results highlight the necessity to create a single QOL instrument capable to measure impacts with sensitivity and specificity and from generic to condition-specific. On the other hand, QOL may have so much intrinsic values and variables that it may not be measurable as a complex concept and described as a single number.

Khadka et al. [15] observed that the impact of DD on QOL measured by SF36 and OQLQ, even before orthognathic surgery, do have differences between different DD problems which are easily observed in OQLQ but was nor observed in SF36. Those authors also report that they were not able to see much difference between the preoperative and postoperative periods in both groups using SF36 [15]. Similarly, Lee et al. [3] in a case control study didn't observe any differences in SF36 domains when compared patients with and without DD, but observed some differences in OHIP and OQLQ. So, which impact on QOL is correct, OQLQ and OHIP or SF36? Or maybe, those authors could report their results like that: 
"facial aesthetics impacts in specific QOL but do not impacts in generic QOL". The results of this present study corroborate this discussion idea that the meaning of the domains are specific for each questionnaire and, while generic questionnaire lacks specificity, the specific one lacks generalities and, for this reason, both may not translate the real impact in QOL. In fact, it is curious and confusing to explore QOL since it has an ambiguous concept for which a precise and consensual definition has yet to be agreed [ $\underline{3}]$.

\section{CONCLUSIONS}

Within the limitations of this study a few conclusions can be draw:

- The impact of dentofacial deformity was more pronounced in female Brazilian population but only observed in generic oral health-related (Oral Health Impact Profile) and condition-specific (Orthognathic Quality of Life Questionnaire) quality of life questionnaires.

- Age of patients with dentofacial deformity produced impacts over quality of life in different ways and according to the applied questionnaire. As older is the patient greater is the negative impact on quality of life mainly in facial aesthetics and oral function domains (Orthognathic Quality of Life Questionnaire), and the increase of age produce more limitations due to physical health and more claims of pain (Short Form Health Survey).
Interaction between age and gender may produce different impacts in patients with dentofacial deformity. Female patients with dentofacial deformity showed that as age increase the impact over facial aesthetics also increase but improve the emotional well being (Short Form Health Survey), while for male patients as age progress, greater is the limitations due to physical health (Short Form Health Survey), however, there are a increase of generic quality of life as a whole (Visual Analogue Scale), and the social disability due oral health problems (Oral Health Impact Profile) get improved.

- Domains of Orthognathic Quality of Life Questionnaire, Oral Health Impact Profile and Short Form Health Survey showed unaccepted distances in the pattern of answer rising doubts of their ability to assess quality of life as a generic and broad concept.

- There is a necessity to create a single quality of life instrument capable to measure impacts with sensitivity and specificity and from a generic concept to condition-specific health problem.

\section{ACKNOWLEDGMENTS AND DISCLOSURE STATEMENTS}

The authors report no conflicts of interest related to this study.

\section{REFERENCES}

1. Cunningham SJ, Garratt AM, Hunt NP. Development of a condition-specific quality of life measure for patients with dentofacial deformity: I. Reliability of the instrument. Community Dent Oral Epidemiol. 2000 Jun;28(3):195-201. [Medline: 10830646] [doi: 10.1034/j.1600-0528.2000.280305.x]

2. Study protocol for the World Health Organization project to develop a Quality of Life assessment instrument (WHOQOL). Qual Life Res. 1993 Apr;2(2):153-9. [Medline: $\underline{\text { 8518769] }}$

3. Lee S, McGrath C, Samman N. Quality of life in patients with dentofacial deformity: a comparison of measurement approaches. Int J Oral Maxillofac Surg. 2007 Jun;36(6):488-92. [Medline: 17339101] [doi: 10.1016/j.ijom.2007.01.011]

4. Al-Ahmad HT, Al-Sa'di WS, Al-Omari IK, Al-Bitar ZB. Condition-specific quality of life in Jordanian patients with dentofacial deformities: a comparison of generic and disease-specific measures. Oral Surg Oral Med Oral Pathol Oral Radiol Endod. 2009 Jan;107(1):49-55. [Medline: 18718795] [doi: 10.1016/j.tripleo.2008.05.040]

5. Choi WS, Lee S, McGrath C, Samman N. Change in quality of life after combined orthodontic-surgical treatment of dentofacial deformities. Oral Surg Oral Med Oral Pathol Oral Radiol Endod. 2010 Jan;109(1):46-51. [Medline: 20123378] [doi: 10.1016/j.tripleo.2009.08.019]

6. Proffit WR, White RP, Sarver DM. Preface. In: Proffit WR, White RP, Sarver DM, editors. Contemporary Treatment of Dentofacial Deformity. CV Mosby; St Louis, Mo: 2003. p. vii.

7. Soh CL, Narayanan V. Quality of life assessment in patients with dentofacial deformity undergoing orthognathic surgery--a systematic review. Int J Oral Maxillofac Surg. 2013 Aug;42(8):974-80. [Medline: 23702370] [doi: $10.1016 /$ j.ijom.2013.03.023] 
8. Bock JJ, Odemar F, Fuhrmann RA. Assessment of quality of life in patients undergoing orthognathic surgery. J Orofac Orthop. 2009 Sep;70(5):407-19. [Medline: 19997999] [doi: 10.1007/s00056-009-9903-4]

9. Murphy C, Kearns G, Sleeman D, Cronin M, Allen PF. The clinical relevance of orthognathic surgery on quality of life. Int J Oral Maxillofac Surg. 2011 Sep;40(9):926-30. [Medline: 21616638] [doi: 10.1016/j.ijom.2011.04.001]

10. Bortoluzzi MC, Manfro R, Soares IC, Presta AA. Cross-cultural adaptation of the orthognathic quality of life questionnaire (OQLQ) in a Brazilian sample of patients with dentofacial deformities. Med Oral Patol Oral Cir Bucal. 2011 Aug 1; 16(5):e694-9. [Medline: 20711138] [doi: 10.4317/medoral.16938]

11. Gava EC, Miguel JA, de Araújo AM, de Oliveira BH. Psychometric properties of the Brazilian version of the Orthognathic Quality of Life Questionnaire. J Oral Maxillofac Surg. 2013 Oct;71(10):1762.e1-8. [Medline: 24040950] [doi: 10.1016/j.joms.2013.05.020]

12. Slade GD, Spencer AJ. Development and evaluation of the Oral Health Impact Profile. Community Dent Health. 1994;11(1):3-11. [Medline: $\underline{8193981]}$

13. Pires CP, Ferraz MB, de Abreu MH. Translation into Brazilian Portuguese, cultural adaptation and validation of the oral health impact profile (OHIP-49). Braz Oral Res. 2006;20(3):263-8. [Medline: 17119711] [doi: 10.1590/S1806-83242006000300015]

14. Nicodemo D, Pereira MD, Ferreira LM. Effect of orthognathic surgery for class III correction on quality of life as measured by SF-36. Int J Oral Maxillofac Surg. 2008;37(2):131-4. [Medline: 17919889] [doi: 10.1016/j.ijom.2007.07.024]

15. Khadka A, Liu Y, Li J, Zhu S, Luo E, Feng G, Hu J. Changes in quality of life after orthognathic surgery: a comparison based on the involvement of the occlusion. Oral Surg Oral Med Oral Pathol Oral Radiol Endod. 2011 Dec;112(6):719-25. [Medline: 21458328] [doi: 10.1016/j.tripleo.2011.01.002]

16. Gift HC, Atchison KA, Dayton CM. Conceptualizing oral health and oral health-related quality of life. Soc Sci Med. 1997 Mar;44(5):601-8. [Medline: 9032828] [doi: 10.1016/S0277-9536(96)00211-0]

17. Allison PJ, Locker D, Feine JS. Quality of life: a dynamic construct. Soc Sci Med. 1997 Jul;45(2):221-30. [Medline: 9225410] [doi: 10.1016/S0277-9536(96)00339-5]

18. Esperão PT, de Oliveira BH, de Oliveira Almeida MA, Kiyak HA, Miguel JA. Oral health-related quality of life in orthognathic surgery patients. Am J Orthod Dentofacial Orthop. 2010 Jun;137(6):790-5. [Medline: 20685534] [doi: 10.1016/j.ajodo.2008.08.031]

\section{To cite this article:}

Bortoluzzi MC, de Camargo Smolarek P, Claudino M, Campagnoli EB, Manfro R.

Impact of Dentofacial Deformity on Quality of Life: Age and Gender Differences Evaluated Through OQLQ, OHIP and SF36. J Oral Maxillofac Res 2015;6(3):e3.

URL: http://www.ejomr.org/JOMR/archives/2015/3/e3/v6n3e3.pdf

doi: $10.5037 /$ jomr.2015.6303

Copyright $\odot$ Bortoluzzi MC, de Camargo Smolarek P, Claudino M, Campagnoli EB, Manfro R. Published in the JOURNAL OF ORAL \& MAXILLOFACIAL RESEARCH (http://www.ejomr.org), 30 September 2015.

This is an open-access article, first published in the JOURNAL OF ORAL \& MAXILLOFACIAL RESEARCH, distributed under the terms of the Creative Commons Attribution-Noncommercial-No Derivative Works 3.0 Unported License, which permits unrestricted non-commercial use, distribution, and reproduction in any medium, provided the original work and is properly cited. The copyright, license information and link to the original publication on (http://www.ejomr.org) must be included. 